\title{
Somatic stability of microsatellite loci in Eastern white pine, Pinus strobus L.
}

\author{
D Cloutier ${ }^{1}$, D Rioux ${ }^{2}$, J Beaulieu ${ }^{2}$ and DJ Schoen ${ }^{1}$ \\ ${ }^{1}$ Department of Biology, McGill University, Montreal, Quebec, Canada H3A 1B1; ${ }^{2}$ Canadian Forest Service, Laurentian Forestry Centre, \\ Sainte-Foy, Quebec, Canada G1V 4C7
}

\begin{abstract}
Variation at nuclear- and chloroplast-encoded microsatellite loci was studied among and within clonally propagated individuals of Eastern white pine. Total DNA was extracted and assayed from gamete-bearing tissue (megagametophytes) located on six different branch positions on each of 12 individual genets. No within-individual variation was observed among 12 loci studied. Estimates of numbers of mitotic cell divisions required to produce the tissue used as
\end{abstract}

Keywords: trees; marker loci; somatic mutation

\section{Introduction}

Unlike animals, the germ line in plants is not sequestered early in development, and thus gametes may arise from cell lineages that have undergone many mitotic divisions after zygotes have formed (Klekowski, 1988). If errors of DNA replication accompany mitosis and are not selectively removed during vegetative growth of the plant (eg, by cell lineage sorting), they can be passed on to the gametes (Klekowski, 1988). It has been argued that somatic mutation may play an important role in producing adaptive variability among plant shoots (Whitham and Slobodchikoff, 1981; Antolin and Strobeck, 1985; Walbot, 1996), in allele frequency change within populations (Orive, 2001), and in life-history patterns of inbreeding depression and mating system evolution (Morgan, 2001). If somatic mutations are passed on to gametes this may result in genomic mutation rates that are higher in plants than in animals, especially in long-lived plants where there may be many somatic cell divisions prior to gamete production (Klekowski and Godfrey, 1989).

There is evidence for the occurrence of somatic mutations in plants (Whitham and Slobodchikoff, 1981; Antolin and Strobeck, 1985; Schaal, 1987; Klekowski, 1988; Gill et al, 1995; Kovalchuk et al, 2000b). Withinindividual variation for polygenic and cytogenetic traits has been documented by several authors (Lewis et al, 1971; Klekowski, 1988; Klekowski and Godfrey, 1989). In addition, molecular genetic variation has been detected among naturally occurring clones in several plant species (Schaal and Learn, 1988; Capossela et al, 1992; Tuskan et al, 1996). Such somatic variation might be expected to

Correspondence: DI Schoen, Department of Biology, 1205 Avenue Docteur Penfield, McGill University, Montreal, Quebec, Canada H3A 1B1

E-mail: dan.schoen@mcoill.ca

Received 18 March 2002; accepted 7 October 2002 the source of genomic DNA were obtained by combining tree growth and anatomical data. This allowed for the calculation of upper bound estimates of numbers of mutations per locus per somatic cell division. The estimated somatic mutation rate was found to be substantially lower than those published for genomic microsatellite mutation rates in other plant species.

Heredity (2003) 90, 247-252. doi:10.1038/sj.hdy.6800221

be most common at loci with high mutation rates, eg, as reported in some cases for microsatellite DNA sequences (Weber and Wong, 1993; Schlötterer et al, 1998; Udupa and Baum, 2001). There is, however, little information about the stability of microsatellite loci during somatic development of plants (Klekowski, 1988; Smith and Devey, 1994; Gill et al, 1995; Elsik et al, 2000). Given the increasing use of microsatellites markers in genetic analyses of long-lived plants, it is important to characterize their stability within individuals. In this study, we report the results of an investigation of somatic mutation in the Eastern white pine, Pinus strobus L. Information useful for gauging the rate of somatic mutation was obtained by combining genetic, growth, and anatomical data. Rather than restricting the analysis solely to variation expressed within the vegetative body of the plant, this study examines tissue that has differentiated into gamete-bearing structures (megagametophytes), thereby allowing us to determine the potential for chimeric transmission of somatically occurring mutations at microsatellite loci.

\section{Materials and methods}

\section{Tree and tissue sampling}

Tree sampling was conducted in a P. strobus breeding orchard set up by the Canadian Forest Service near CapTourmente, Quebec, Canada. Propagation of the trees located in this orchard was originally carried out by selecting a number of adjacent shoots (ramets) from selected parent trees (genets) in natural populations and grafting them to separate rootstocks in the orchard. Two ramets each from 12 different genets were sampled for a total of 24 trees. From each ramet, female cones were collected at three branch positions that were marked for measurements made later on in the study (see below). Seeds were extracted from the cones in September 2000, 

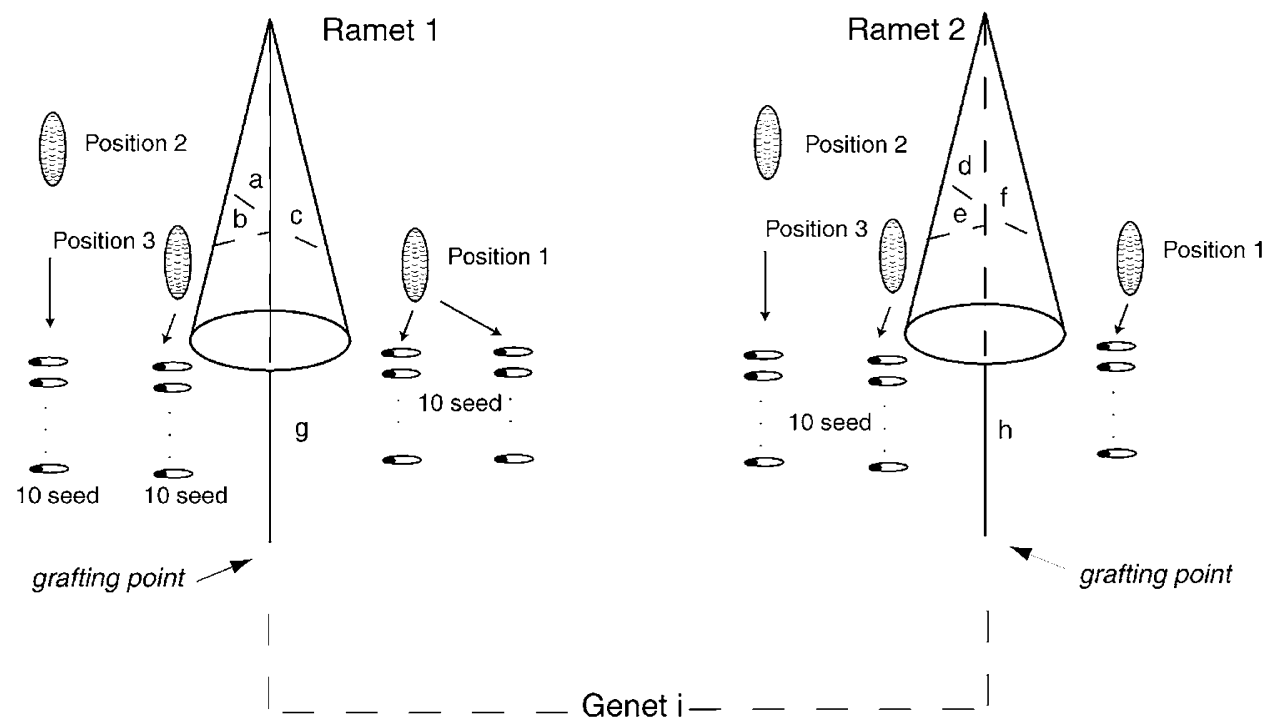

Figure 1 Scheme for sampling megagametophytes from individual ramets. Cones were collected from three positions per ramet, and megagametophytes were extracted from seeds within these cones. The total vegetative growth separating all sampled cones was determined by summing tree segments $a-h$.

kept separately in bags, and stored in a dry container at $4^{\circ} \mathrm{C}$. All genetic analyses were carried out using haploid megagametophyte tissue. Depending upon the analysis, DNA was extracted either from individual megagametophytes and analysed separately, or from the pooled tissue of 10 megagametophytes collected from cones at a single branch position. Figure 1 outlines the sampling scheme.

\section{Microsatellite analyses}

Genomic DNA was extracted from megagametophytes using the DNeasy plant mini-kit (Quiagen, Valencia, CA, USA). DNA samples were screened for variation at eight nuclear and four chloroplast microsatellite loci (Table 1). The choice of loci has been made on the basis of the level of polymorphism detected in previous studies (Echt et al, 1996). The more highly variables of these loci were selected since they are expected to have the highest mutation rate. DNA sequences of the PCR primers for the loci examined in this study have been published elsewhere (Cato and Richardson, 1996; Echt et al, 1996; Vendramin et al, 1996). The PCR reaction and amplification conditions were as described by Echt et al (1996, 1999). Fluorescently labeled amplified PCR products were separated by electrophoresis on a $41 \mathrm{~cm}$ polyacrylamide gel (Li-Cor model $4000 \mathrm{~L}$ automatic DNA sequencer) (Li-Cor, Lincoln, NE, USA).

Genotypes of individual genets at each microsatellite locus were determined by examining gel-banding patterns of PCR amplification products obtained using template DNA extracted from a single branch position (ie, DNA from a set of 10 pooled megagametophytes taken from a single cone). As this procedure is based on inferring the parent genotype from the combined haploid genotypes of meiotically derived products, it is possible that one of the two alleles at a locus for which the parent is heterozygous was not detected. However, with 10 megagametophytes per genet, the probability of such an event is small $\left(P=0.5^{10}<0.001\right.$, if we consider that the
Table 1 Microsatellite loci examined in 12 genets of $P$. strobus

\begin{tabular}{llcc}
\hline $\begin{array}{l}\text { Microsatellite } \\
\text { loci }\end{array}$ & Location & Repeat & $\begin{array}{c}\text { Number of alleles } \\
\text { observed }\end{array}$ \\
\hline$r p s-6^{\mathrm{a}}$ & Nucleus & $(\mathrm{T})_{6}(\mathrm{AC})_{n}(\mathrm{~T})_{6}$ & 5 \\
$r p s-12^{\mathrm{a}}$ & Nucleus & $(\mathrm{AC})_{n}$ & 7 \\
$r p s-20^{\mathrm{a}}$ & Nucleus & $(\mathrm{AC})_{n}(\mathrm{AT})_{6}$ & 8 \\
$r p s-25 b^{\mathrm{a}}$ & Nucleus & $(\mathrm{AC})_{n} \mathrm{AG}(\mathrm{AT})_{9}$ & 2 \\
$r p s-39^{\mathrm{a}}$ & Nucleus & $(\mathrm{AC})_{n}$ & 3 \\
$r p s-50^{\mathrm{a}}$ & Nucleus & $(\mathrm{AC})_{n}$ & 9 \\
$r p s-60^{\mathrm{a}}$ & Nucleus & $(\mathrm{AC})_{n}(\mathrm{AT})_{7}$ & 7 \\
$r p s-118 b^{\mathrm{a}}$ & Nucleus & $(\mathrm{AC})_{n}$ & 6 \\
$c p S S R-1^{\mathrm{b}}$ & Chloroplast & $(\mathrm{A})_{n}(\mathrm{G})_{n}$ & 2 \\
$c p S S R-5^{\mathrm{b}}$ & Chloroplast & $(\mathrm{T})_{n}$ & 1 \\
$P t 63718^{\mathrm{c}}$ & Chloroplast & $(\mathrm{T})_{n}$ & 2 \\
$P t 71936^{\mathrm{c}}$ & Chloroplast & $(\mathrm{T})_{n}$ & 2 \\
& & &
\end{tabular}

${ }^{\mathrm{a} E c h t}$ et al (1996). ${ }^{\mathrm{b} C}$ Cato and Richardson (1996). 'Vendramin et al (1996).

allele of only one megagametophyte could be detected). To assay the parental genotype at other branch positions, and thereby establish the presence of somatically occurring mutations passed on to seeds, this procedure was applied to pooled megagametophytes collected from cones at each of the remaining five positions per genet.

The genetic interpretation of the microsatellite banding patterns was confirmed by genotypic segregation analyses conducted with each locus, using sets of individual megagametophytes taken from three separate parent trees. If no amplification was observed from the DNA at one locus, but amplification of the expected size product was observed at a control locus, the tree was assumed to have a segregating nonamplifying 'null' allele at the tested locus. When only one allele was observed from the three genets (Table 3), segregation analyses allowed us to discriminate between homozygotes and heterozygotes for null alleles. 
Estimates of number of cell divisions

For each ramet, the length of vegetative growth separating the branch positions where cones were sampled was estimated. This was done by measuring the length from each branch position to a common position on the tree trunk, and then summing the distances. The distance from this common position to the position where the ramet (scion) was grafted onto the rootstock was added to this measure. The same set of measurements was made for the paired ramet of this genet, and finally, the two ramet lengths were summed to obtain the total vegetative growth per genet (Figure 1).

To convert vegetative growth into a number of mitotic divisions, estimates of mean cell length are required. Branch tips were collected in May 2001, and radial sections of the shoot extending back through the past 2 years of vegetative growth were used. Tissue sections $(1 \mathrm{~cm}$ long) were cut in half and fixed in FAA (4\% formaldehyde, 5\% acetic acid, and $47.5 \%$ ethanol) for $21 \mathrm{~h}$. They were dehydrated by increasing the ethanol concentration over several days. Ethanol was gradually replaced by $n$-butanol, and the samples were put in $n$ butanol:Paraplast+ (Oxford, St Louis, MO, USA) (1:1) overnight at $60^{\circ} \mathrm{C}$, followed by transfer to three baths of pure Paraplast+ over 10 days. Longitudinal sections $(7 \mu \mathrm{m})$ were obtained with a Leica Biocut rotary microtome (Heidelberg, Germany), deparaffined and stained with $0.05 \%$ toluidine blue $\mathrm{O}$ and $0.25 \%$ safranin $\mathrm{O}$, and examined with a Leitz Orthoplan microscope. Cell lengths were determined from shoot sections. As selected in other studies (Brown and Sommer, 1992), the lengths of the pith cells along the median longitudinal axis of the shoot were measured with a micrometer.

Since cell enlargement accompanies cell division, measures of cell length were taken within the apical meristem (the region of active cell division), directly below the apical meristem (where cells begin to differentiate into pith tissue), and within mature pith tissue (where cell enlargement is completed). Cells within each of 10 separate longitudinal files of cells per section were counted. These files of cells were randomly selected throughout each location. Cell divisions that do not give rise to vegetative growth (eg, cell divisions within cones) were not considered in this study, but as these account for a small fraction of overall cell divisions, the introduced error is considered to be negligible.

\section{Results}

\section{Microsatellite variation among and within genets}

Microsatellite variation among separate genets was detected at all but one of the loci surveyed (Table 2). Variation in the number of alleles per locus and number of genotypes observed was higher for nuclear as compared with chloroplast loci, a finding that accords with the results of Provan et al (1999). The average observed heterozygosity per tree was $0.57(\mathrm{SD}=0.23)$. Four of the nuclear microsatellite loci appear to produce null alleles (Table 2). Analysis of microsatellite genotypes from individual megagametophytes produced by single genets confirmed the presence of segregation in families from trees judged to be heterozygous on the basis of the analysis of pooled megagametophytes (Table 3).

No microsatellite mutation events were detected within genets; that is, alleles detected in megagametophytes at one branch position were identical to those detected at other positions within the genet (Figure 2). This was true of both nuclear and chloroplast loci. However, it is possible that mutations to null alleles could have occurred and remained undetected.

Table 2 Genotypes of ramets tested at nuclear- and chloroplast-encoded microsatellite loci

\begin{tabular}{|c|c|c|c|c|c|c|c|c|c|}
\hline \multirow[b]{2}{*}{ Genet } & \multirow[b]{2}{*}{ rps-6 } & \multirow[b]{2}{*}{ rps-12 } & \multirow[b]{2}{*}{ rps-20 } & \multicolumn{2}{|c|}{ Nuclear Loci } & \multirow[b]{2}{*}{ rps-50 } & \multirow[b]{2}{*}{ rps-60 } & \multirow[b]{2}{*}{ rps- $118 b$} & \multirow[b]{2}{*}{ cpSSR 1/cpSSR 5/Pt63718/Pt71936 } \\
\hline & & & & rps-25b & rps-39 & & & & \\
\hline 77116 & $170^{\mathrm{a}} / 170$ & $169 / 189$ & $138 / 140$ & $113 / 113$ & $170 / 170$ & $170 / 176$ & $251 / 267$ & $138 / 138$ & $239 / 102 / 98 / 146$ \\
\hline 77122 & $170 / 170$ & $189 / 189$ & $140 / 148$ & Null/null & $170 / 180$ & $168 / 170$ & $259 / 259$ & $152 / 152$ & $239 / 102 / 98 / 146$ \\
\hline 77130 & $169 / 170$ & $185 / 185$ & $138 / 142$ & $111 / 111$ & $170 / 170$ & $170 / 172$ & $251 / 271$ & $152 / 152$ & $240 / 102 / 98 / 146$ \\
\hline 78508 & $170 / 170$ & $187 / 187$ & $140 / 154$ & Null/null & $170 / 172$ & $168 / 174$ & Null/null & $160 / 160$ & $239 / 102 / 98 / 146$ \\
\hline 82531 & $169 / 170$ & $185 / 185$ & $140 / 152$ & $111 / 111$ & $172 / 172$ & $170 / 172$ & Null/null & $152 / 152$ & $240 / 102 / 98 / 146$ \\
\hline 84541 & $172 / 188$ & Null/null & $148 / 148$ & $111 / 111$ & $172 / 172$ & $168 / 168$ & $268 / 268$ & $160 / 160$ & $240 / 102 / 98 / 146$ \\
\hline 84544 & $170 / 196$ & $187 / 187$ & $138 / 140$ & Null/null & $170 / 172$ & $160 / 170$ & $264 / 264$ & $142 / 176$ & $239 / 102 / 98 / 146$ \\
\hline 84547 & $169 / 170$ & $151 / 151$ & $138 / 146$ & Null/null & $170 / 170$ & $168 / 170$ & Null/null & $138 / 152$ & $240 / 102 / 98 / 146$ \\
\hline 84548 & $170 / 170$ & $185 / 185$ & $138 / 154$ & Null/113 & $172 / 172$ & $168 / 180$ & $269 / 271$ & $152 / 152$ & $239 / 102 / 99 / 146$ \\
\hline 84550 & $169 / 170$ & $185 / 185$ & $144 / 154$ & Null/null & $170 / 170$ & $170 / 182$ & Null/null & $162 / 162$ & $239 / 102 / 98 / 146$ \\
\hline 84554 & $169 / 170$ & $157 / 185$ & $152 / 152$ & $111 / 111$ & $170 / 172$ & $170 / 174$ & $259 / 259$ & $162 / 162$ & $240 / 102 / 98 / 146$ \\
\hline 845102 & $169 / 172$ & Null/195 & $138 / 140$ & Null/111 & Null/172 & $168 / 178$ & Null/null & $138 / 152$ & $240 / 102 / 98 / 147$ \\
\hline
\end{tabular}

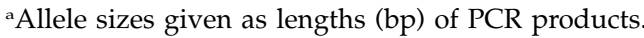

Table 3 Allele segregation in megagametophytes of the genets tested

\begin{tabular}{|c|c|c|c|c|c|c|c|c|}
\hline \multirow[t]{2}{*}{ Genet } & \multicolumn{8}{|c|}{ Nuclear loci } \\
\hline & rps-6 & rps-12 & rps-20 & rps-25b & rps-39 & rps-50 & rps-60 & rps- $118 b$ \\
\hline 77122 & 170,170 & 189,189 & 140,148 & Null,null & 170,180 & 168,170 & 259,259 & 152,152 \\
\hline 84548 & 170,170 & 185,185 & 138,154 & Null,113 & 172,172 & 168,180 & 269,271 & 152,152 \\
\hline 845102 & 169,172 & Null,195 & 138,140 & Null,111 & Null,172 & 168,178 & Null,null & 138,152 \\
\hline
\end{tabular}




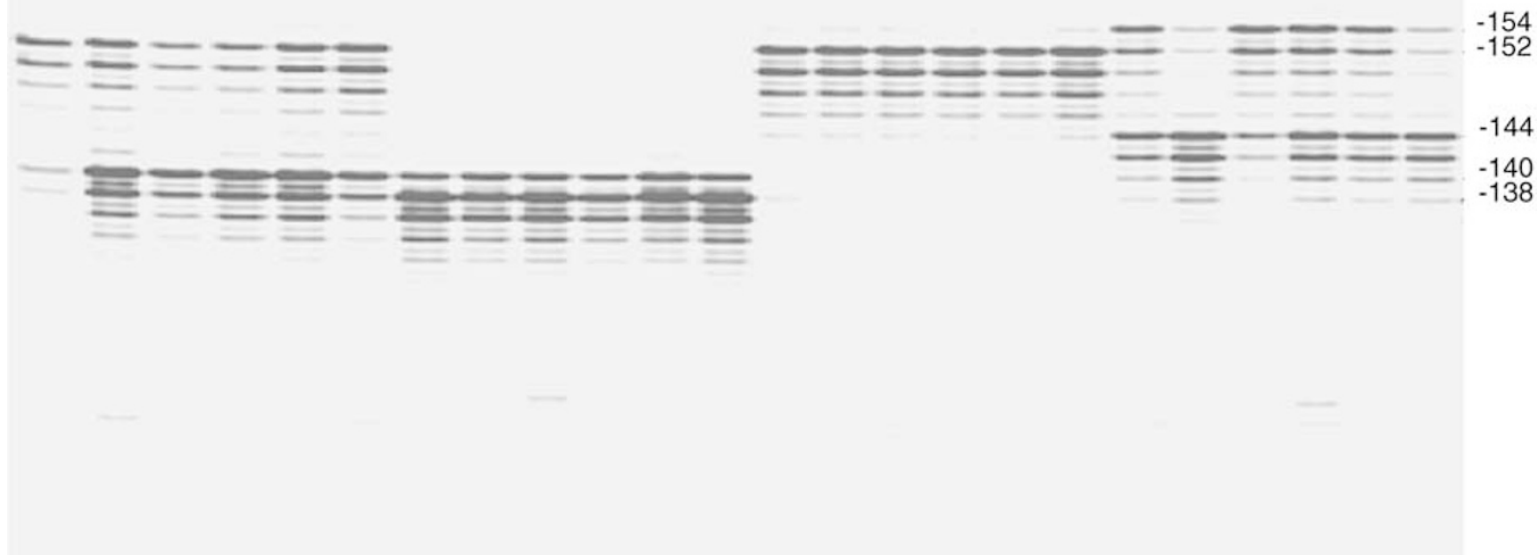

Figure $2 \mathrm{Gel}$ image showing lack of evidence for microsatellite mutation at the rps-20 locus within genets of $P$. strobus. From left to the right, the four genets are 82531 (lanes 1-6), 845102 (lanes 7-12), 84554 (lanes 13-18), and 84550 (lanes 19-24). Similar lack of variation was observed for all loci and genets tested. Numbers in margin represent length of the PCR product (bp).

\section{Estimates of number of cell divisions}

The total vegetative growth unit separating the sampled branch positions within each genet varied between 15 and $21 \mathrm{~m}$ (Table 4). Microscopic investigation of shoot sections revealed that cell lengths increased from within the apical meristem (mean length of 236 cells $=21.2 \mu \mathrm{m}$, $\mathrm{SD}=1.4 \mu \mathrm{m}$ ) through to 1-year-old shoot tissue (mean length of 143 cells $=70.4 \mu \mathrm{m}, \mathrm{SD}=6.6 \mu \mathrm{m}$ ), where they attained their maximum size. These cell length values are similar to those observed in P. taeda (Brown and Sommer, 1992).

Rather than basing estimates of number of cell divisions per unit of vegetative growth on cell lengths obtained from only a single region of the shoot, estimates were based on both the smallest and largest mean cell lengths observed within the shoot tips (those from the apical meristem and 1-year-old region). Such a procedure takes into account the fact that cell enlargement and cell division may occur simultaneously within meristems (Brown and Sommer, 1992); that is, the possibility that there is no one characteristic size for an actively dividing meristematic cell. This yields two different estimates of cell divisions per unit vegetative growth, which should include the true value: 47170 and 14205 divisions per metre of vegetative growth.

\section{Discussion}

Our data suggest that microsatellites are stable genetic markers within Eastern white pine, as no evidence of mutation was observed during somatic growth and gamete formation. These findings are in accord with other analyses of microsatellite loci inheritance. For instance, in two separate studies of three-generation pedigrees in pine, no mutations were observed (Elsik et al, 2000; Smith and Devey, 1994). One possible exception is the study conducted by Fisher et al (1998),
Table 4 Vegetative growth separating sampled cone positions

\begin{tabular}{lccc}
\hline Genet & $\begin{array}{c}\text { Vegetative } \\
\text { growth }(m)\end{array}$ & Genet & $\begin{array}{c}\text { Vegetative } \\
\text { growth }(m)\end{array}$ \\
\hline 77116 & 21.13 & 84544 & 19.74 \\
77122 & 20.65 & 84547 & 15.60 \\
77130 & 19.73 & 84548 & 16.70 \\
78508 & 21.22 & 84550 & 17.82 \\
82531 & 19.51 & 84554 & 17.01 \\
84541 & 20.41 & 845102 & 19.86 \\
\hline
\end{tabular}

who reported the appearance of nonparental alleles at a single nuclear microsatellite locus in $6 \%$ of the progeny and megagametophytes from $P$. radiata crosses. Unfortunately, the sampling design of the study prevents any inference about the origin of mutations (somatic or germline) as well as their rate of occurrence. Moreover, each of the novel alleles observed by Fisher et al (1998) was at least four repeat units different from the parental allele, and thus contradicts the expectation that mutations at microsatellite loci should involve single repeat unit changes following slippage during DNA replication (Ellegren, 2000; Schlötterer, 2000). Such hypermutable microsatellite loci seem to be the exception rather than the rule, since mutations have never been reported in any other study conducted in P. strobus (eg Echt et al, 1996), in other pine species (eg Smith and Devey, 1994; Hicks et al, 1998; Elsik et al, 2000), and in conifers in general (eg Ven et al, 1996; Pfeiffer et al, 1997; Khasa et al, 2000; Hodgetts et al, 2001; Rajora et al, 2001). Overall, these results suggest that the use of microsatellites as markers in longlived organisms (eg, in marker-assisted selection and population studies) should, in general, provide reliable results.

There is little quantitative information available on rates of somatic mutation in plants. Somatic base 
substitution frequency in plants has been estimated to be two to three orders of magnitude higher than in other organisms (Kovalchuk et al, 2000b). Genomic mutation rates for microsatellite loci in plants have been estimated to fall within the range of $10^{-2}-10^{-3}$ for nuclear-encoded loci with tri- and dinucleotide repeats (Kovalchuk et al, 2000a; Udupa and Baum, 2001) to $10^{-5}$ for chloroplastencoded loci with mononucleotide repeats (Provan et al, 1999). Comparison of estimated mutation rates of microsatellite loci in related shorter- and longer-lived annual plant species of the genus Cicer led Udupa and Baum (2001) to argue that mutations occurring during somatic growth contribute to enhanced levels of genomic mutation in plants; a two- to three-fold increase in genomic mutation rates was found for the longer-lived species of Cicer. The results from the present investigation do not support the interpretation that somatic mutations can contribute significantly to the rate of genomic mutation.

As no mutations were observed in this study, direct calculation of the rate of somatic mutation was not possible. One can, however, use probabilistic methods to set upper boundaries on the mutation rate per cell division for each locus. For instance, in the case of a single tree and single diploid locus, if the haploid mutation rate per cell division per locus is $\mu$, and $r$ cell division have occurred, the probability of observing no mutations at this locus can be taken from the zero term of the Poisson distribution with parameter $2 r \mu$. This probability is $P=\mathrm{e}^{-2 r \mu}$. To find a boundary at the $P=5 \%$ level for $\mu$, one can solve for $\mu$ in the previous equation, setting $P=0.05$. Using this procedure with the data in Table 4 and the higher and lower estimates of cell division per metre of stem growth (see above) yields estimates of somatic mutation for the nuclear microsatellite loci of $1.38 \times 10^{-7}$ and $4.59 \times 10^{-7}$ mutations per cell division, respectively. For the haploid, chloroplast loci, the procedure is similar, except we use the equation $P=\mathrm{e}^{-r \mu}$. This gives estimates of $2.77 \times 10^{-7}$ and $9.19 \times 10^{-7}$ mutations per cell division.

Since the apical region of the meristem may divide less often than adjacent regions, the above procedure may underestimate the true somatic mutation rate. In a detailed cytological study, Owens and Molder (1973) quantified mitotic activity of different regions of the shoot apical meristem in the related pine family member, Pseudotsuga menziesii. The regions studied included the apical and rib meristems. Cell divisions within the apical region give rise to the rib meristems, which contribute to vegetative growth but ultimately cease to divide within the first year. Only the apical region contains permanently dividing cells (apical initials). Thus, when tracing tissue located in different regions of the plant body back to a common 'ancestral' meristematic cell, it is the number of cell divisions within the apical meristematic region that should be counted. To quantify the relative contribution of cell division activity in the apical versus rib zones, Owens and Molder (1973) calculated mitotic frequencies using Feulgen staining methods. In the most active growth stage, that is, late bud-scale initiation, the mitotic frequency of the apical zone was 0.8 , while in the rib zone it was 5.6. The proportion of cell divisions that rise from the mitotic activity in the apical zone can, therefore, be approximated as $0.8 / 5.6=0.14$. If these relative rates are also characteristic of the apical meristem in P. strobus, then the estimated numbers of cell divisions separating different positions along the shoot axis (Table 4) should be reduced (ie by multiplying by 0.14 ). Doing this would increase the estimated somatic mutation rates at nuclear locus, roughly 10 -fold, to $9.9 \times 10^{-7}$ and $3.3 \times 10^{-6}$ mutations per cell division per locus, respectively, for cell division estimates based on cell lengths of 21.2 and $70.4 \mu \mathrm{m}$. Given the likelihood that most microsatellite mutations are selectively neutral, cell lineage selection probably plays little or no role in distorting these estimates of somatic mutation (Otto and Hastings, 1998; Otto and Orive, 1995).

In theory, such estimates of mutation could also be obtained by pooling information across loci, but because it has been shown that microsatellite mutation rates may differ widely among loci (Di Rienzo et al, 1998; Harr et al, 1998), this approach is probably not warranted. Several factors may contribute to differences in mutation rates among microsatellite loci. They include repeat number, sequence of the repeat motif, length of the repeat unit, flanking sequence, and interruptions in the microsatellite (Ellegren, 2000; Schlötterer, 2000).

The above calculation of the somatic mutation rate also does not take into account mutations to null alleles. Null alleles, however, are thought to occur by base substitution, deletion or insertion within the priming site, and these events are not expected to be as frequent as mutations by slippage at DNA replication.

Estimates of the number of cell divisions separating different positions on an individual tree are difficult to obtain. One possible source of error is that cell length may differ within and along the stem. Our estimates of maximum cell length were based on pith cells, but it has been observed that cortex cells were of similar size and would therefore give the same results. Measurements of maximum length of cells were made at $7 \mathrm{~cm}$ from the branch tip (ie in the previous growing year) and hence these cells had completed their elongation. Furthermore, measurements made with two additional white pine branches that had completed their elongation gave similar results to the values reported in this study and in the study of Brown and Sommer (1992) (data not shown). The observed level of variation in maximum cell length is negligible and the estimated somatic mutation rate remains low even when we use higher cell length estimations.

The meristem is perhaps better viewed as a heterogeneous pool of initials, some of them dividing rapidly (ie, the rib meristem) and producing the greater portion of the somatic tissue, while other meristematic initials may act as permanent stem cells (ie, apical meristem). In this study, we proposed a correction for this feature of meristems based on studies conducted with P. menziesii, but it is possible that the extension to P. strobus meristems is not accurate. Meristem zones of P. menziesii varied in size and in mitotic activity at different times of the growing season (Owens and Molder, 1973). It is therefore problematic to circumscribe precisely the different regions of the meristem - instead there may be a gradual transition of mitotic activity from the apical to the rib meristem. Additional studies are needed to quantify the role of apical initials as stem cells for meristematic tissues in plants. Perhaps this pattern of cell division activity within meristems may have evolved as a means to minimize errors during somatic DNA replication from being passed on from one generation to the next. 


\section{Acknowledgements}

We thank Pierre-Olivier Cheptou, Marie Deslauriers, Craig Echt, Frank Ewers, Jim Grob, Manuel Lamothe, Aura Navarro-Quezada, Marie Simard, John Owens, and GG Vendramin for their advice and assistance with this study. The Natural Sciences and Engineering Research Council of Canada provided financial support through its scholarship program to DC and an Operating Grant to DJS. DC also acknowledges financial support from the Canadian Forest Service.

\section{References}

Antolin MF, Strobeck C (1985). The population genetics of somatic mutation in plants. Am Nat 126: 52-62.

Brown CL, Sommer HE (1992). Shoot growth and histogenesis of trees possessing diverse patterns of shoot development. Am J Bot 79: 335-346.

Capossela A, Silander Jr JA, Jansen RK, Bergen B, Talbot DR (1992). Nuclear ribosomal DNA variation among ramets and genets of white clover. Evolution 46: 1240-1247.

Cato SA, Richardson TE (1996). Inter- and intraspecific polymorphism at chloroplast SSR loci and the inheritance of plastids in Pinus radiata D. Don. Theor Appl Genet 93: 587592.

Di Rienzo A, Donnelly P, Toomajian C, Sisk B, Hill A, Petzl-Erler $M$ et al (1998). Heterogeneity of microsatellite mutations within and between loci and implications for human demographic histories. Genetics 148: 1269-1284.

Echt CS, May-Marquardt P, Hseih M, Zahorchak R (1996). Characterization of microsatellite markers in Eastern white pine. Genome 39: 1102-1108.

Echt CS, Vendramin GG, Nelson CD, Marquardt P (1999). Microsatellite DNA as shared genetic markers among conifer species. Can J For Res 29: 365-371.

Ellegren H (2000). Microsatellite mutations in the germline: implications for evolutionary inference. Trends Genet 16: 551558.

Elsik CG, Minihan VT, Hall SE, Scarpa AM, Williams CG (2000). Low-copy microsatellite markers for Pinus taeda L. Genome 43: 550-555.

Fisher PJ, Richardson TE, Gardner RC (1998). Characteristics of single- and multi-copy microsatellites from Pinus radiata. Theor Appl Genet 96: 969-979.

Gill DE, Chao L, Perkins SL, Wolf JB (1995). Genetic mosaicism in plants and clonal animals. Annu Rev Ecol Syst 26: 423-444.

Harr B, Zangerl B, Brem G, Schlötterer C (1998). Conservation of locus specific microsatellite variability across species: a comparison of two Drosophila sibling species D. melanogaster and D. simulans. Mol Biol Evol 15: 176-184.

Hicks M, Adams D, O'Keefe S, Macdonald E, Hodgetts R (1998). The development of RAPD and microsatellite markers in lodgepole pine (Pinus contorta var. latifolia). Genome 41: 797805.

Hodgetts RB, Aleksiuk MA, Brown A, Clarke C, Macdonald E, Nadeem $S$ et al (2001). Development of microsatellite markers for white spruce (Picea glauca) and related species. Theor Appl Genet 102: 1252-1258.

Khasa PD, Newton CH, Rahman MH, Jaquish B, Dancik BP (2000) Isolation, characterization, and inheritance of microsatellite loci in Alpine larch and Western larch. Genome 43: 439-448.

Klekowski EJ (1988). Mutation, Developmental Selection, and Plant Evolution. Columbia University Press: New York.

Klekowski EJ, Godfrey PJ (1989). Aging and mutation in plants. Nature 340: 389-391.
Kovalchuk O, Dubrova YE, Arkhipov A, Hohn B, Kovalchuk I (2000a). Wheat mutation after Chernobyl. Nature 407: 583.

Kovalchuk I, Kovalchuk O, Hohn B (2000b). Genome-wide variation of the somatic mutation frequency in transgenic plants. EMBO J 19: 4431-4438.

Lewis WH, Oliver RL, Luikart TK (1971). Multiple genotypes in individuals of Claytonia virginica. Science 172: 564-565.

Morgan MT (2001). Consequences of life history evolution for inbreeding depression and mating system evolution in plants. Proc $R$ Soc London B 268: 1817-1824.

Orive ME (2001). Somatic mutations in organisms with complex life histories. Theor Popul Biol 59: 235-249.

Otto SP, Hastings IM (1998). Mutation and selection within the individual. Genetica 103: 507-524.

Otto SP, Orive ME (1995). Evolutionary consequences of mutation and selection within an individual. Genetics 141: 1173-1187.

Owens JN, Molder M (1973). A study of DNA and mitotic activity in the vegetative apex of Douglas fir during the annual growth cycle. Can J Bot 51: 1395-1409.

Pfeiffer A, Olivieri AM, Morgante M (1997). Identification and characterization of microsatellites in Norway spruce (Picea abies K.). Genome 40: 411-419.

Provan J, Soranzo N, Wilson NJ, Goldstein DB, Powell W (1999). A low mutation rate for chloroplast microsatellites. Genetics 153: 943-947.

Rajora OP, Rahman MH, Dayanandan S, Mosseler A (2001). Isolation, characterization, inheritance and linkage of microsatellite DNA markers in white spruce (Picea glauca) and their usefulness in other spruce species. Mol Gen Genet 264: 871-882.

Schaal BA (1987). Somatic variation and genetic structure in plant populations. In: Davy AJ, Hutchings MJ, Watkinson AR (eds) Plant Population Ecology, Blackwell Scientific Publications: Boston. pp 47-58.

Schaal BA, Learn GH (1988). Ribosomal DNA variation within and among plant populations. Ann Mol Bot Gard 75: 12071216.

Schlötterer CR (2000). Evolutionary dynamics of microsatellite DNA. Chromosoma 109: 365-371.

Schlötterer CR, Ritter R, Harr B, Brem G (1998). High mutation rate of a long microsatellite allele in Drosophila melanogaster provides evidence for allele-specific mutation rates. Mol Biol Evol 15: 1269-1274.

Smith DN, Devey ME (1994). Occurrence and inheritance of microsatellites in Pinus radiata. Genome 37: 977-983.

Tuskan GA, Francis KE, Russ SL, Romme WH, Turner MG (1996). RAPD markers reveal diversity within and among clonal and seedling stands of aspen in Yellowstone National Park, USA. Can J For Res 26: 2088-2098.

Udupa SM, Baum M (2001). High mutation rate and mutational bias at (TAA) ${ }_{n}$ loci in chickpea (Cicer arietinum L). Mol Gen Genet 265: 1097-1103.

Van de Ven WTG, McNicol RJ (1996). Microsatellites as DNA markers in Sitka spruce. Theor Appl Genet 93: 613-617.

Vendramin GG, Lelli L, Rossi P, Morgante M (1996). A set of primers for the amplification of 20 chloroplast microsatellites in Pinaceae. Mol Ecol 5: 595-598.

Walbot V (1996). Sources and consequences of phenotypic and genotypic plasticity in flowering plants. Trends Plant Sci 1: 27-32.

Weber JL, Wong C (1993). Mutation of human short tandem repeats. Hum Mol Genet 2: 1123-1128.

Whitham TG, Slobodchikoff CN (1981). Evolution by individuals, plant-herbivore interactions, and mosaics of genetic variability: the adaptive significance of somatic mutations in plants. Oecologia 49: 287-292. 